\title{
Simulation and Performance Analysis of Propylene-Propane Splitter in Petroleum Refinery Case Study
}

\author{
Aniediong M. Umo and Etim N. Bassey
}

\begin{abstract}
The separation of propane and propylene mixture requires high capital cost and high energy consumption. This challenge is obvious since propane and propylene have similar molecular size and physical properties. Therefore in the last few years, many processes have been surveyed as alternatives to distillation for this separation. However, researches carried out on these techniques indicated that they have not yet shown sufficient advantage over the distillation process. Therefore the objective of this work is to explore the possibility of establishing optimum operating parameters for better operation of the distillation process for realizing higher product quality and improved energy consumption. In this paper the simulation and analysis of an existing propylene-propane distillation column with 150 trays were carried out. The result of the response optimization showed a product yield of $95 \%$ propylene in the distillate from a minimum of $94 \%$ yield, reduced reflux ratio from 10.2 to 10.02 and about $0.4 \times 10^{6} \mathrm{kcal} / \mathrm{h}$ of reboiler energy input was saved. It was evident from these results that optimum parameters had been established for better control of the splitter column case study with the potential of achieving higher product quality and improved energy consumption.
\end{abstract}

Index Terms-Energy improvement, performance analysis, petroleum refinery, simulation, splitter.

\section{INTRODUCTION}

Propylene is one of the most important intermediate petrochemical products. Over the years, it has maintained a remarkable growth in the market on account of increasing demand for polypropylene which absorbs more than $60 \%$ of all the propylene produced worldwide [1]. Other important propylene derivatives include acrylic acid, acrylonitrile, cumene, phenol, gasoline blend, trimmers and tetramers for detergents. Propylene is commonly produced as a by-product of naphtha and light gas oil feedstock in the steam cracking (SC) and the fluidized catalytic cracking (FCC) units. Currently SC accounts for about $60 \%$ while FCC accounts for about $30 \%$ of propylene production [2].

The high cost of crude oil in the past few years made it necessary for producers to seek cheaper feedstock for the refineries. The use of natural gas liquids (NGLs) and shale oil which have high composition of ethane oil have greatly reduced the by-product propylene. Thus to meet the propylene market demand producers are gradually adopting

Manuscript received June 20, 2016; revised October 17, 2016

Aniediong M. Umo was with the Department of Chemical and Petroleum Engineering, University of Uyo, Nigeria (e-mail: umoaniediong@gmail.com).

Etim N. Bassey is with the Department of Chemical/Petrochemical Engineering, Akwa Ibom State University, Ikot Akpaden, Nigeria (e-mail: enbassey@yahoo.co.uk). the on-purpose propylene technology; propane dehydrogenation, olefin metathesis, and methanol to propylene [2]-[4]. However, irrespective of the propylene manufacturing route, the product is always a propylene/propane mixture which must be separated. The purity of the propylene will depend on the grade; for the polymer grade a minimum of $99.5 \%$ purity is required, for chemical grade $90-95 \%$ purity and the refinery grade $50-70 \%$ purity are required [3].

Since propane and propylene have similar molecular size and physical properties, their separation is challenging. This separation is mostly carried out in a distillation column with about 150-200 trays, with a reflux ratio as high as 10-20 and at a high pressure of about 16-26 atm. The process requires high capital cost and high energy consumption. To maximize profit, as energy prices rise, energy efficiency, together with optimizing product quality and maximizing high-value product yields have become more important to producers [5] However, for many years, the standard operating philosophy for distillation process was to maximize reflux for maximum separation. When energy was reconsidered inexpensive, this philosophy held sway [6]. Therefore in the last few years, many processes like absorption, adsorption, extractive-distillation, and membrane techniques have been surveyed as alternatives to distillation for this separation [3], [7], [8]. However, researches carried out on these techniques indicated that they have not yet shown sufficient advantage over the distillation process. For example in the use of extractive-distillation, the thermodynamic properties of the investigated extraction solvents tend to exhibit insufficient selectivity to yield an economically viable process. Similarly, the use of adsorption method usually requires several steps to reach a desirable product purity in addition to the use of complicated regeneration cycles, low olefin loadings and high capital costs requirements thus making the system less attractive compared to distillation process [3], [9].

Until better alternatives are developed or the present techniques are improved to a level that shows sufficient advantage over distillation, effort must be made to optimize the distillation column to achieve the required result. Therefore the objective of this work is to explore the possibility of establishing optimum operating parameters for better operation of the process for realizing higher product quality and improved energy consumption.

\section{Methodology}

\section{A. Problem Definition}

The aim of this work is to study the interactive effect of 
those process variables involved in the operation of the propane-propylene splitter in this case study. Sensitivity analysis will provide a tool that is useful in the optimization of the operating condition of the splitter.

The propylene - propane splitter unit in this case study which is conceptually illustrated in Fig. 1, is part of a polypropylene plant which comprises propylene purification, polymerization, additive and extrusion units. The plant was designed to produce 35,000 metric tonnes of polypropylene resin per year [10].The purification area upgrades 73 mole percent propylene from a fluid catalytic cracking (FCC) unit to a minimum of 94 moles percent in the propylene - propane splitter.

The propylene-propane splitter is made up of a column of $3 \mathrm{~m}$ diameter containing a total of 150 trays, a reboiler and an overhead condenser. The purified propylene recovered at the top is condensed, part of which is returned as reflux and the other part fed to the propylene drying unit, while the propane is drawn off at the reboiler.

\section{B. Process Simulation}

The simulation of the propane-propylene splitting unit was carried out using Hysys Simulation tool and the result obtained from the simulation was analyzed using Minitab 14 statistical software. In this work, the number of theoretical stages required for the separation, feed stages location, reflux ratio, column pressure and reboiler duty were evaluated. In the performance analysis it was possible to visualize the effect of two variables on a specific design condition using response surface plots. The efficient operating criteria considered was mole fraction of propylene in the distillate, which should be a minimum of 0.94 .

For the simulation, the initial operating data of the column consisted of $55.32 \mathrm{~kg}$ mole/hr propylene, reflux ratio of 10.2 , distillate flow rate of $246.98 \mathrm{~kg}$ mole $/ \mathrm{hr}$, column pressure of 18.23atm and feed temperature of $53{ }^{\circ} \mathrm{C}$.

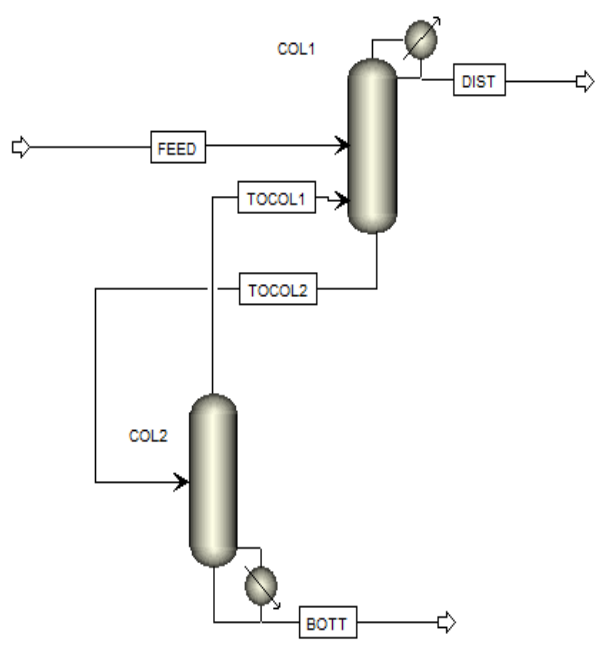

Fig. 1. Schematic of propane-propylene splitter.

\section{RESULT AND DISCUSSION}

The initial operating conditions, material and energy balances obtained from the simulation are shown in Table I.
The response surface methodology was used to obtain the surface and contour plots from the simulated data to describe the interactive effect of the process variables on percentage propylene yield in the distillate. The column was optimized to obtain a yield of $95 \%$ propylene and above in the distillate which exceeds the $94 \%$ minimum specified for the propane-propylene splitter in the case study plant.

\section{A. Effect of Reflux Ratio and Column Pressure}

The effect of reflux ratio and column pressure on the percentage composition of propylene in the distillate is presented in Fig. 2. It was observed that at a column pressure of 22 atm and reflux ratio of 10 , the percent of propylene obtained in the distillate was in the range of $94.0 \%$ to $94.4 \%$. At a lower pressure of $18 \mathrm{~atm}$ using the same reflux ratio of 10 , the percentage composition of propylene was observed to increase to a higher range of $94.8 \%$ and $95.2 \%$. Thus lowering the column pressure of the splitter unit would favor the purity of propylene in the distillate but would lead to an increased reboiler duty. Thus it is advisable that, selecting the column operating pressure must ensure that the dew point of the distillate is above that which can easily be obtained with cooling liquid. In general the contour plots in Fig. 2, Fig. 3 and Fig. 4 indicate that increase in the reflux ratio increases the percentage propylene in the distillate while a decrease in pressure will favour high yield of propylene. Thus from the plots it was found that for a yield of propylene above $95.2 \%$ a column pressure of less than $20 \mathrm{~atm}$ and a reflux ratio of 10.2 were required.

TABLE I: INITIAL PLANT OPERATING Data

\begin{tabular}{llll}
\hline Item & Feed & Product & Bottom \\
\hline Material stream & & & \\
\hline Vapour Fraction & 1.00 & 0.00 & 0.00 \\
\hline Temperature [C] & 53.00 & 41.75 & 54.24 \\
\hline Pressure [bar] & 18.23 & 17.22 & 19.25 \\
\hline $\begin{array}{l}\text { Molar Flow } \\
{[\mathrm{kgmole} / \mathrm{h}]}\end{array}$ & 290.70 & 246.96 & 43.74 \\
\hline $\begin{array}{l}\text { Mass Flow } \\
{[\mathrm{kg} / \mathrm{h}]}\end{array}$ & 12344.37 & 10419.80 & 1924.57 \\
\hline $\begin{array}{l}\text { Liquid Volume } \\
\text { Flow [m3/h] }\end{array}$ & 23.82 & 20.03 & 3.79 \\
\hline $\begin{array}{l}\text { Heat Flow } \\
{[\mathrm{kcal} / \mathrm{h}]}\end{array}$ & -227856.96 & -43.83 & -1156869.77 \\
\hline Component Mole Fraction & & \\
\hline Propylene & 0.81 & 0.946 & 0.043 \\
\hline Propane & 0.19 & 0.054 & 0.957 \\
\hline
\end{tabular}

\section{B. Effect of Feed Stage Location}

The interactive effects of feed with pressure and reflux ratio in Fig. 3 and 4 are very similar. It was observed that as the feed stage goes from stage 20 to stage 60 the purity of propylene in the distillate increases. However, at a feed stage of 70 a gradual decline in composition of propylene is observed. The analysis further shows that, for optimum yield of propylene, the feed stage should be located between stages 56 and 75. However, the operator may choose not to obtain the optimum propylene yield of $95.5 \%$ and above since the pressure and reflux ratio may lead to high reboiler duty.

\section{Reboiler Duty Consideration}

The effect of the pressure and reflux ratio on the reboiler duty (Qreboiler) on the one hand and of the pressure and feed 
stage on the reboiler duty on the other hand are shown in the surface plots in Fig. 5 and 6 respectively. As it is evident from Fig. 5, high percent yield of propylene requires high reflux ratio and lower pressure which result in increased reboiler duty. A similar surface plot in Fig. 6, shows that a high propylene percent in the distillate is promoted by a high feed stage and a reduction in column pressure which again increase the reboiler heat duty. In this respect more utilities will be required which will negatively affect the operating cost and profitability of the plant.

The aim of any process plant is to make profit by minimising the cost of production. The cost of energy is a major factor to be considered especially in a developing country like Nigeria where energy is very expensive. The simulation and the analysis of the unit should offer an avenue for proper monitoring and optimization of the operation.

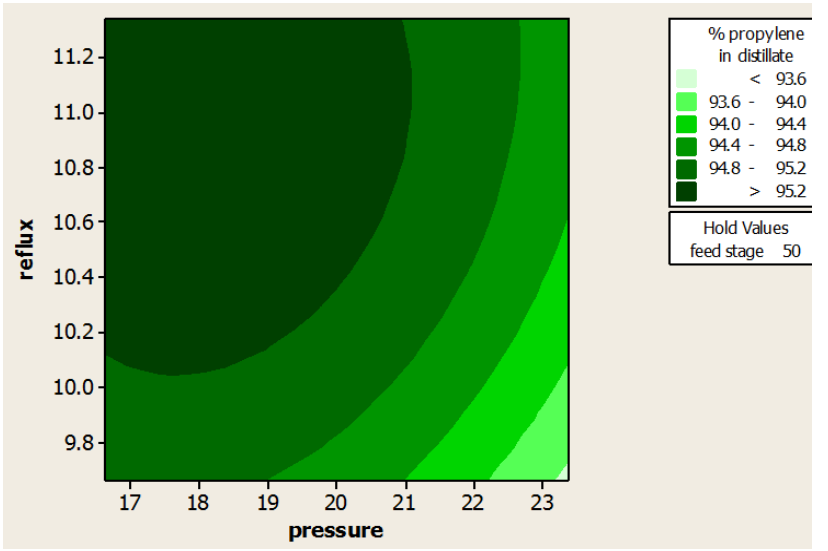

Fig. 2. Contour plot of $\%$ propylene in distillate vs. reflux ratio, pressure (atm).

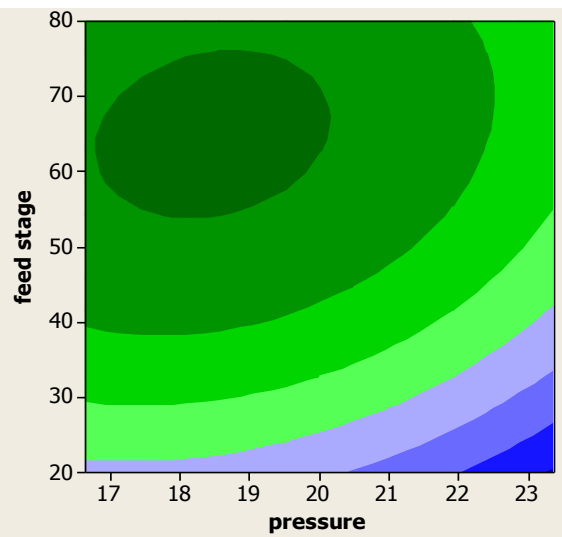

Fig. 3. Contour plot of $\%$ propylene in distillate vs. feed stage, pressure (atm).

\section{Response Optimization}

Fig. 7 is the response optimization of the propane-propylene splitter unit carried out with Minitab 14 statistical software to maximize propylene yield in the distillate and minimize the reboiler duty.

The efficient operating criteria considered for the splitter unit were a minimum of 0.94 mole fraction and a target of 0.95 mole fraction of propylene in the distillate which represented the desirability limits for propylene maximization. The simulated propylene-propane plant in the case study produced $9747.8 \mathrm{~kg} / \mathrm{h}$ of polymer grade propylene with a quality of $94.72 \%$ propylene. The reboiler energy requirement for the column obtained in the simulation was $7.5 \times 10^{6} \mathrm{Kcal} / \mathrm{h}$ and this was considered as upper limit for reboiler heat duty which was subject to be minimised.
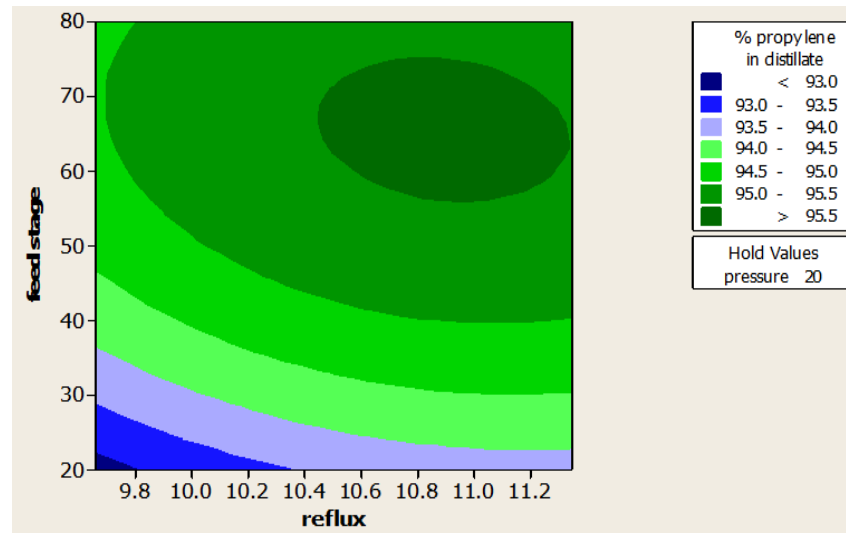

Fig. 4. Contour plot of $\%$ propylene in distillate vs. feed stage, reflux ratio.

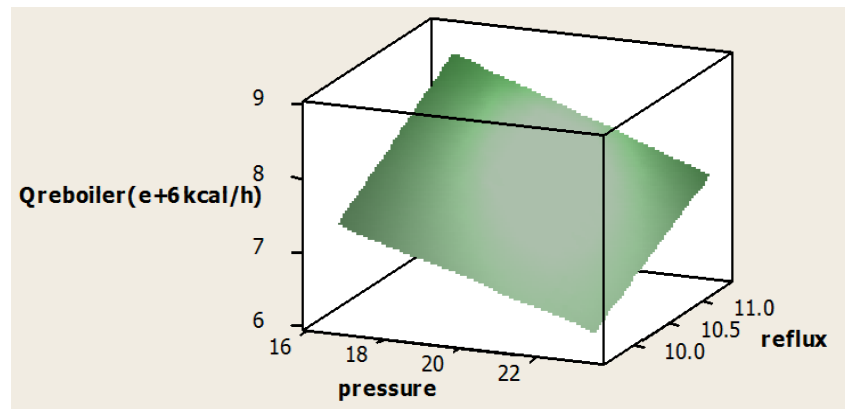

Fig. 5. Surface plot of qreboiler $(\mathrm{e}+6 \mathrm{kcal} / \mathrm{h})$ vs reflux ratio, pressure (atm) (hold value; feed stage 50)

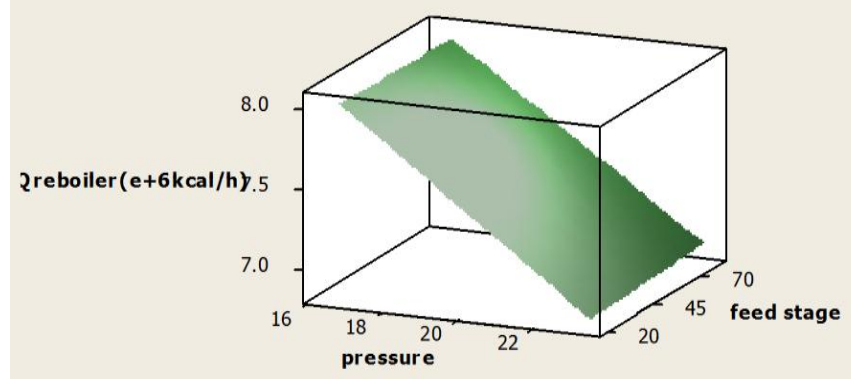

Fig. 6. Surface plot of qreboiler (e+6kcal/h) vs feed stage, pressure (atm). (hold value; reflux ratio 10.5 )

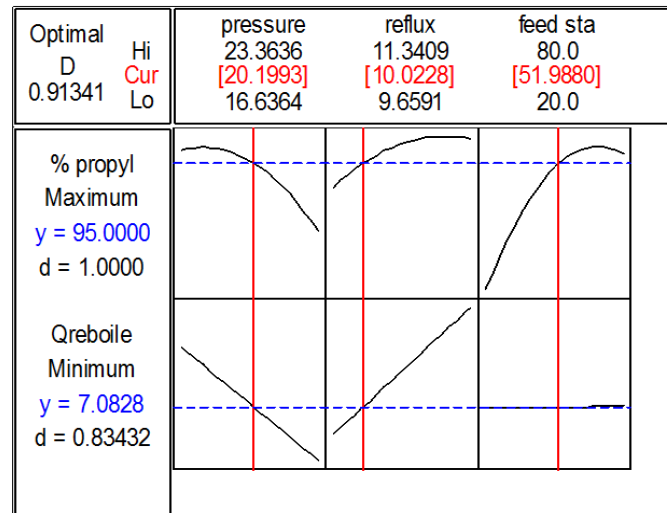

Fig. 7. Response optimization for propylene yield.

The result of the optimization gave $>95 \%$ propylene in the distillate and $7.08 \times 10^{6} \mathrm{Kcal} / \mathrm{h}$ heat flow in the reboiler was achieved at a column pressure of 20.199 atm, reflux ratio 10.023 and at a feed stage of 52 as the optimum condition of 
operation. The result illustrated that despite an increase in the column pressure from 18 atm to $20.2 \mathrm{~atm}$, reduction in reflux ratio from 10.2 to 10.02 , the reboiler heat duty reduced from $7.5 \times 10^{6}$ to $7.08 \times 10^{6} \mathrm{Kcal} / \mathrm{h}$.

\section{CONCLUSION}

Propylene- propane splitter in a petroleum refining case study has been simulated. Analysis of the data and optimization of the column have shown a reduction in reflux ratio from 10.2 to 10.02 , an increase in the column pressure from $18.23 \mathrm{~atm}$ to $20.2 \mathrm{~atm}$, increased percent propylene in the distillate from $94.7 \%$ to $>95 \%$ and a saving of about $0.4 \times 10^{6}$ $\mathrm{kcal} / \mathrm{h}$ in reboiler energy input. The results obtained have led to a better understanding of the process and have therefore provided a guide to its optimum operation and control.

\section{REFERENCES}

[1] M. Heiaritz-Adrain and S. Wenzel, "Advanced propane dehydrogenation," PTQ, pp. 83-91, 2008.

[2] A. Aaron and A. Musaed, "Maximizing propylene production via FCC Technology," Appl Petrochem Res, vol. 5, pp. 377-392, 2015.

[3] F. Marcos, "Progress in the recovery of gaseous olefins.The combined role of membranes, facilitated transport and ionic liquids," Ph.D Thesis, University of Cantabria, Spain, 2013.

[4] L. Rafael, "Refining and Petrochemicals: Challenges and solutions," Presented at Haldor Topsoe Catalytic Forum, August, 2015.

[5] B. Hagger "Improving refinery distillation operations," $P T Q$, Q2, pp. 129-132, 2008.

[6] P. Martin, R. Latour, and A. Lynn "Closed-loop optimisation of distillation energy," Chemical Engineering Progress, pp. 33-37, 1981.

[7] A. Shaheen "Role of catalyst type in the selective separation of olefinic and paraffinic hydrocarbons using xerogel-based adsorbents," Elsevier CARBON, vol. 46, pp. 1003-1009, 2008.

[8] M. Surya, R. Yamuna, T. Sankarshana, F. Ismail, and S. Sridhar "Separation of binary mixtures of propylene and propane by facilitated transport through silver incorporated poly (ether-block-amide) membranes," Oil \& Gas Science and Technology - Rev. IFP Energies nouvelles, vol. 70, no. 2, pp. 381-390, 2015.

[9] P. Jeroen, "Membranes for ethylene/ethane separation," Ph.D Thesis, University of Twente, Enschede, Netherlands, 2013.

[10] B. Odigo, "Evaluation of Propane - propylene splitter in warri refining and petrochemical company," Nigerian Society of Engineers Technical Report, 2003.

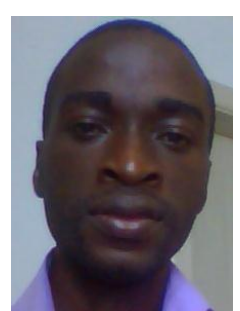

Aniediong M. Umo was born in 1985 in Ukpom Abak, Nigeria. He received his B.Eng. (2011) and M.Eng. (2016) in chemical engineering from the University of Uyo, Akwa Ibom state, Nigeria.

He had served as a quality control Analyst (industrial trainee) Peacock Paint Nigeria Ltd (2009), Presiding Officer Eghosa Grammar School Polling Unit, Edo State Gubernatorial Election July 2012, and was President of National Youth Service Corps
(NYSC) Engineering Community Development Service, Ego, Benin City, July 2012-October 2012. He is currently occupied in process and equipment design in soap manufacturing. His research results are published in four conference papers and journals, which include "Optimization of Ethanol Fermentation of Cassava Wastewater Using Response Surface Method," Global Journal of Engineering Research, 2013. His research activities are process design, modeling, simulation and optimization.

Mr Aniediong was awarded NYSC state merit award in 2012. He served as a member of the secretariat committee NSChE annual conference 2013 in Uyo.

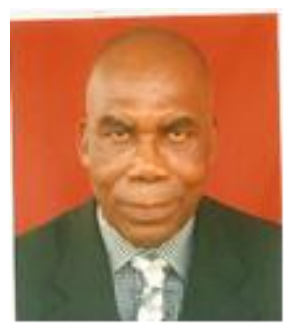

Etim N. Bassey was born in 1945 in Oron, Nigeria. $\mathrm{He}$ obtained his $\mathrm{BSc}$ (1972) ; MSc (1974) in chemical and petrochemical engineering from the now Lvov Polytechnic National University, Ukraine and $\mathrm{PhD}$ (1986) in chemical engineering from University of Bradford, England.

He worked in the steel industry in Ajaokuta and Warri, Nigeria from 1975-2005. In 2006 he joined the University of Uyo, Nigeria as a senior lecturer and became the head of Department of Chemical and Petroleum Engineering from 2010-2012. He joined the Akwa Ibom State University, Ikot Akpaden, Nigeria in 2012 where he is a professor in the Department of Chemical /Petrochemical Engineering. His publications include "Study of the Contribution of Carbon IV and Carbon II Oxides in Methanol Synthesis with Modified Kinetic Model," International Journal of Scientific Research and Education, 2015; "Kinetic Models Evaluation in Methanol Production for improved Process Design," International Journal of Innovative Research and Development, 2015. His research interests are in areas of process design and integration, optimization, materials engineering, energy systems and environmental process engineering.

Prof. Bassey is a Registered Professional Engineer in Nigeria, a Fellow of both the Nigerian Society of Chemical Engineers and the Nigerian Society of Engineers, and a Senior member of the American Institute of Chemical Engineers. He served as a Country Representative in the International Iron and Steel Institute Committee on Technology from 1990-1996. Prof Bassey is a recipient of 1986 Carl Hanson Travel Award of the British Institution of Chemical Engineers for his Research in Solvent Extraction; Nigerian Society of Chemical Engineers "Pinnacle Holdings" Award in 1992, for Development of a process for beneficiation of low grade Nigerian iron ore into superconcentrade for Direct Reduction Steel production, National Prize Winner for RMRDC Process Equipment and Plants Design in 2004. 